\title{
EFICIÊNCIA DO HERBICIDA FORAMSULFURON + IODOSULFURON NO CONTROLE DE PLANTAS DANINHAS NA CULTURA DO MILHO
}

\author{
Robinson Luiz Contiero', Mario César Lopes ${ }^{1}$, Mauricio Bloedorn², Idelvan \\ Bonadiman Blanco ${ }^{2}$ \\ ${ }^{1}$ Eng ${ }^{\circ}$. Agrônomo, Dr., Professor, UNIOESTE/MCR, Rua Pernambuco, 1777, Caixa \\ Postal 91, CEP. 85.960-000, Marechal Cândido Rondon/PR, Fone/Fax: $\left.{ }^{* *} 45\right)$ 254- \\ 3216, e-mail: robinson@unioeste.br \\ ${ }^{2}$ Acadêmico do Curso de Agronomia da UNIOESTE/MCR, Rua Pernambuco, 1777, \\ Caixa Postal 91, CEP. 85.960-000, Marechal Cândido Rondon/PR, Fone/Fax: $\left({ }^{* *} 45\right)$ \\ 254-3216.
}

\section{RESUMO}

O objetivo do trabalho foi avaliar a eficiência do herbicida foramsulfuron + lodosulfuron, aplicado em pós-emergência, para o controle de plantas daninhas na cultura do milho. O ensaio foi conduzido na UNIOESTE - Campus de Marechal Cândido Rondon-PR, no período de outubro/2000 a março/2001. A aplicação dos herbicidas em pós-emergência foi realizada quando o milho estava com 4 a 5 folhas totalmente desprendidas do cartucho, utilizando-se um pulverizador costal a pressão constante $\left(\mathrm{CO}_{2}\right)$ de $2,1 \mathrm{kgf} / \mathrm{cm}^{2}$, barra equipada com 6 bicos leque XR Teejet 110-02 e consumo de calda de $200 \mathrm{l} / \mathrm{ha}$. $\mathrm{O}$ delineamento experimental utilizado foi o de blocos ao acaso, com 4 repetições e os tratamentos foram os seguintes: foramsulfuron (35 e 45,3 g/ha), foramsulfuron + iodosulfuron $(36+2,4$ e $45+3 \mathrm{~g} / \mathrm{ha})$, foramsulfuron + atrazine $(35+1000$ e $45,5+1000 \mathrm{~g} / \mathrm{ha})$, nicosulfuron ( $50 \mathrm{~g} / \mathrm{ha})$, testemunha capinada e testemunha sem capina. Todos os produtos utilizados apresentaram excelente controle das plantas daninhas existentes nas unidades experimentais do ensaio. Nenhum herbicida causou qualquer tipo de injúria na cultura, que comprometesse seu desenvolvimento. Quanto ao parâmetro produção, não se observou diferença significativa entre os produtos testados, sendo porém todos superiores à testemunha sem capina.

Palavras chave: Controle químico, foramsulfuron, iodosulfuron, Zea mays.

\section{EFFICIENCY OF HERBICIDE FORAMSULFURON + IODOSULFURON TO CONTROL WEEDS IN CORN PLANTATIONS}

\begin{abstract}
The objective of this study was to determine efficiency of herbicide foramsulfuron + iodosulfuron applied as post-emergence to control weeds in corn plantations. The experiment was established at UNIOESTE - Campus de Marechal Cândido Rondon, from October 2000 to March 2001. The postemergence application of the herbicides was executed at the $4-5$ fully expanded corn leaves. We used a backpack pulverizer at constant pressure $\left(\mathrm{CO}_{2}\right)$ of 2,1 $\mathrm{Kgf} / \mathrm{cm}^{2}$ and a bar equipped with 6 XR Teejet 110-02 nozzles that delivered 200 I/ha. The experimental design was a randomized block design with 4 repetitions. Treatments consisted of: foramsulfuron ( 35 and $45.3 \mathrm{~g} / \mathrm{ha}$ ), foramsulfuron +
\end{abstract}


iodosulfuron $(36+2.4$ e $45+3 \mathrm{~g} / \mathrm{ha})$, foramsulfuron + atrazine $(35+1000$ and $45.5+1000 \mathrm{~g} / \mathrm{ha})$, nicosulfuron $(50 \mathrm{~g} / \mathrm{ha})$, hoed and non hoed control. All products had excellent control of weeds present on the experimental plots. None of the herbicides caused any injury to the corn. No significant difference in corn production was detected as result of the tested herbicides. On the other hand, all treatments yielded corn production superior to the non hoed control.

Key words: Chemical control, foramsulfuron, iodosulfuron, Zea mays.

\section{INTRODUÇÃO}

O milho (Zea mays L.) é uma das culturas que atinge a maior área de plantio no Brasil, num total de aproximadamente 11 milhões e 600 mil hectares, na safra 1999/2000 (IBGE, 2001). Nossa contribuição mundial é, porém, ainda bem inferior à dos países mais produtivos, o que é devido principalmente à baixa produtividade (Ramos, 1992).

A cultura de milho, apesar de ser considerada como de boa capacidade competitiva (Heemst, 1986) e ser enquadrada entre o grupo de culturas que mais sombreiam o solo (Keeley \& Thullen, 1978), sofre intensa interferência das plantas daninhas, com sérios prejuízos no crescimento, na produtividade e na operacionalização de colheita (Ramos, 1992; Viswanath, 1977). Portanto, reduzir ou eliminar esta interferência consiste numa pratica indispensável à produção agrícola (Rossi et al., 1996).

O controle de plantas daninhas, é, sem dúvida, um dos fatores determinantes na produtividade do milho. A American Weed Science (1984), citada por Kissman (1990), relata perdas de 12\%, o que equivaleria a 19,1 milhões de toneladas, na cultura do milho nos Estados Unidos da América, devido à presença de plantas daninhas. No Brasil, os efeitos negativos detectados no crescimento e produtividade da cultura do milho, devido à presença de plantas daninhas já foram observados por diversos autores (Carvalho \& Galli, 1993; Velini et al., 1993; Silva et al., 1993; Rossi et al., 1996; Pinto et al., 2000; Constantin et al., 2000; Carvalho et al., 2001; Osipe \& Lopes, 2002; Pitelli et al., 2002).

Segundo Carvalho et al. (2001), existem diversos métodos para se controlar as plantas daninhas numa cultura, que variam desde os mecânicos e os culturais, até o uso de produtos químicos. Na cultura do milho, o uso de herbicidas tem sido bastante utilizado, em função do melhor rendimento operacional obtido durante seu desenvolvimento principalmente devido ao fato de poderem ser utilizados em grandes áreas e em condições de maior índice pluviométrico.

Foramsulfuron e lodosulfuron são duas novas moléculas do grupo das sulfoniluréias, utilizadas para o controle de gramíneas e de folhas largas, respectivamente. Inibem a ação da enzima acetolactato sintetase (ALS), conseqüentemente inibindo a produção de proteínas pela interferência na biossíntese de aminoácidos como valina, leucina e isoleucina. As duas moléculas apresentam completa translocação sistêmica, sendo absorvidos rapidamente pelas folhas, atingindo todas as partes da planta, como as raízes e as regiões meristemáticas (pontos de crescimento).

A velocidade de ação depende da espécie de planta daninha, do ambiente e da dose utilizada. Condições ambientais que promovem o rápido crescimento da planta, também promovem forte atividade herbicida. 
Sendo novas moléculas herbicidas, são necessárias várias pesquisas para comprovação de sua eficiência e seletividade à cultura do milho.

Dentro deste contexto, o objetivo do presente trabalho foi avaliar a eficiência do herbicida foramsulfuron + iodosulfuron para o controle de plantas daninhas na cultura do milho, comparando-o com produtos já existentes no mercado.

\section{MATERIAL E MÉTODOS}

O ensaio foi conduzido na Estação Experimental de Marechal Cândido Rondon, pertencente ao Núcleo de Estações Experimentais da UNIOESTE - Campus de Marechal Cândido Rondon, no período de outubro/2000 a março/2001.

A semeadura foi realizada em 13/10/2000, utilizando-se o híbrido Dina Milho 766, com espaçamento de 0,80 m entre linhas e 4,6 plantas por metro linear, e a colheita foi realizada em 01/03/2001. Após a semeadura ocorreu uma chuva de $10 \mathrm{~mm}$ e a emergência ocorreu 5 dias após a semeadura

A adubação de plantio consistiu em $300 \mathrm{~kg} / \mathrm{ha}$ do adubo 08-30-20 e a adubação de cobertura foi feita com $175 \mathrm{~kg} / \mathrm{ha}$ de uréia, dividida em duas aplicações.

O delineamento experimental utilizado foi o de blocos ao acaso, com 9 tratamentos e 4 repetições, sendo as parcelas constituídas de 4 linhas de milho espaçadas de $0,80 \mathrm{~m} \mathrm{(3,2} \mathrm{m),} \mathrm{com} \mathrm{10,0} \mathrm{m} \mathrm{de} \mathrm{comprimento.} \mathrm{Dessa}$ forma, a área total de cada parcela constituiu-se de $32,0 \mathrm{~m}^{2}$. Como área útil para as avaliações, considerou-se as duas linhas centrais de milho.

No Quadro 1 encontram-se as informações sobre os tratamentos, utilizados no experimento e no Quadro 2 encontram-se as precipitações ocorridas durante a condução do experimento.

As plantas daninhas incidentes nas unidades experimentais foram as seguinte, com suas respectivas densidades: amendoim-bravo (Euphorbia heterophylla) - $59 \mathrm{pl} / \mathrm{m}^{2}$, guanxuma (Sida rhombifolia) - $23 \mathrm{pl} / \mathrm{m}^{2}$, picão-preto (Bidens pilosa) - $25 \mathrm{pl} / \mathrm{m}^{2}$ e capim-marmelada (Brachiaria plantaginea) - 33 $\mathrm{pl} / \mathrm{m}^{2}$.

A aplicação dos herbicidas em pós-emergência foi realizada em 03/11/2000, quando o milho se encontrava em média com 4 a 5 folhas totalmente desprendidas do cartucho, utilizando-se um pulverizador costal de pressão constante $\left(\mathrm{CO}_{2}\right)$, com 6 bicos leque XR Teejet 110-02 espaçados de $0,50 \mathrm{~m}$, pressão de $2,1 \mathrm{kgf} / \mathrm{cm}^{2}$ e volume de calda de $200 \mathrm{~L} / \mathrm{ha}$.

As condições climáticas no momento da aplicação eram: temperatura do ar: $24,7^{\circ} \mathrm{C}$; umidade relativa do ar: $80 \%$, céu parcialmente nublado; velocidade do vento: $1,0 \mathrm{~km} / \mathrm{h}$ e solo úmido.

Quando da aplicação dos produtos, as plantas daninhas latifoliadas estavam com 2 a 4 folhas e as gramíneas com 1 perfilho em média.

Para o controle de Lagarta-do-cartucho (Spodoptera frugiperda,) realizaram-se 2 aplicações dos inseticidas Lambdacyhalothrin - $150 \mathrm{ml} / \mathrm{ha}$ e Chlorpyrifos $-0,60 \mathrm{l} / \mathrm{ha}$. 
Os demais tratos culturais foram realizados segundo recomendações de órgãos de pesquisa do Estado do Paraná para a cultura do milho.

A eficiência dos herbicidas no controle das plantas daninhas foi avaliada aos 7, 14, 21 e 42 dias após a aplicação (DAA) dos tratamentos, utilizando-se uma escala visual onde $0 \%$ correspondeu a nenhum controle e $100 \%$ correspondeu ao controle total das plantas daninhas. Considerou-se como eficiente o controle superior a $80 \%$.

As avaliações visuais de seletividade foram realizadas aos 7,14 , 21 e 42 dias após a aplicação (DAA) dos tratamentos. Para se determinar o efeito fitotóxico dos herbicidas utilizou-se uma escala de porcentagem de plantas com sintomas de fitotoxicidade, onde $0 \%$ representou nenhuma planta com sintoma e $100 \%$ representou todas as plantas com sintomas.

Para a determinação da produção, colheu-se as duas linhas centrais da parcela de milho, e os dados foram transformados para $\mathrm{kg} / \mathrm{ha}$.

Os dados obtidos foram transformados para $\sqrt{x+0,5} \mathrm{e}$ submetidos a análise de variância pelo Teste $\mathrm{F}$ e as médias foram comparadas pelo teste de Tukey, a 5\% de probabilidade.

\section{RESULTADOS E DISCUSSÃO}

Os resultados de porcentagem de controle de Amendoim-Bravo aos 7, 14, 21 e 42 DAA, são apresentados no Quadro 3. Observa-se que os herbicidas foramsulfuron + iodosulfuron (na dose de $36+2,4 \mathrm{~g} / \mathrm{ha}$ ) $e$ foramsulfuron + atrazine (na dose de $35+1000 \mathrm{~g} / \mathrm{ha}$ ) foram, aos 42 DAA, significativamente inferiores à testemunha capinada, embora tenham apresentado porcentagens de controle de 96,0 e $94,5 \%$, respectivamente.

Os resultados de porcentagem de controle de picão-preto, guanxuma e capim-marmelada aos 7, 14, 21 e 42 DAA, são apresentados nos Quadros 4 a 6.

Pela análise destes quadros, verifica-se que, todos os produtos utilizados, em todas as doses e, em todas as avaliações realizadas apresentaram controle excelente das plantas daninhas existentes na área do experimento, tendo apresentado, mesmo aos 42 DAA, eficiências de controle iguais ou superiores a 97,5\%, o que demonstra não só a eficiência deste novo produto, como também seu poder residual, no controle das plantas daninhas incidentes nas unidades experimentais.

Os dados médios de fitotoxicidade dos herbicidas e de produtividade da cultura estão apresentados no Quadro 7. Os tratamentos herbicidas provocaram sintomas de fitotoxicidade inicial, caracterizados por um leve amarelecimento da folhas da cultura. Nas avaliações subseqüentes, os sintomas foram desaparecendo gradativamente e, aos 21 DAA não mais se constatou nenhuma injúria. Cabe salientar que essas injúrias não provocaram qualquer efeito na produção da cultura.

Os dados de produtividade confirmam os efeitos prejudiciais da competição entre a cultura e as plantas daninhas, efeitos esses já constatados por diversos outros autores (Carvalho \& Galli, 1993; Velini et al., 1993; Silva et al., 1993; Rossi et al., 1996; Pinto et al., 2000; Constantin et al., 2000; Carvalho et al., 2001; Osipe \& Lopes, 2002; Pitelli et al., 2002). A convivência com as 
plantas daninhas prejudicou significativamente a produção da cultura no tratamento testemunha sem capina, ocorrendo uma queda de produção média de $48 \%$.

\section{CONCLUSÕES}

Os herbicidas foramsulfuron (35,0 e $45,5 \mathrm{~g} / \mathrm{ha})$, foramsulfuron + iodosulfuron $(36,0+2,4$ e 45,0 + 3,0 g/ha), nicosulfuron $(50,0 \mathrm{~g} / \mathrm{ha})$ e Foramsulfuron + Atrazine $(35,0+1000$ e 45,5 + 1000) foram eficientes no controle de Euphorbia heterophylla, Bidens pilosa, Sida rhombifolia e Brachiaria plantaginea.

Nas doses utilizadas, nenhum dos herbicidas apresentou sintomas de fitotoxicidade que comprometesse a cultura do milho, sendo, portanto considerados seletivos a essa cultura.

A convivência com as plantas daninhas reduziu a produtividade do milho em $48 \%$, em média, na área da testemunha sem capina.

\section{REFERÊNCIAS BIBLIOGRÁFICAS}

ANDREI, E. Compêndio de defensivos agrícolas. São Paulo: Organização Andrei Editora Ltda. 1999. 672p.

CARVALHO, F.T.; GALLI, A.J.B. Nova formulação de alachlor na seletividade e no controle de plantas daninhas na cultura do milho. In: CONGRESSO BRASILEIRO DE HERBICIDAS E PLANTAS DANINHAS, 19. Londrina, PR, 1993. Resumos... Londrina: SBHED, 1993. p.131.

CARVALHO, F.T.; PERUCHI, M.; PALAZZO, R.R.B. Eficácia de herbicidas no controle, em pós-emergência, de plantas daninhas na cultura do milho. Revista Brasileira de Herbicidas, Brasília: SBCPD, 2001. p.143-147.

CONSTANTIN, J.; OLIVEIRA, R.S.; MACIEL C.D.G.; ROSSI, J.M. Utilização de isoxaflutole e isoxaflutole + atrazina para o manejo de plantas daninhas em milho. In: CONGRESSO BRASILEIRO DE HERBICIDAS E PLANTAS DANINHAS, 22. Foz do Iguaçu, PR, 2000. Resumos... Foz do Iguaçu: SBCPD, 2000. p.280.

HEEMST, H.D.G. The influence of weed competition on crop yield. Agric. Syst., Wageningem, v.18, n.2, p.81-83, 1986.

IBGE (Rio de Janeiro, RJ). Levantamento sistemático da produção agrícola. Disponível: URL: http://www.ibge.gov.br/sidra.htm.

KEELEY, P.E.; THULLEN, R.J. Light requirements of yellow nutseage and light interception by crops. Weed Sci., Champaign, v.26, n.1, p.10-16, 1978. 
KISSMAN, G.K. Controle de plantas infestantes: passado e futuro. In: SEMANA DO CONTROLE DE PLANTAS DANINHAS, X, 1990. bandeirantes. Anais... Bandeirantes: FFALM, 1990. p.1-22.

OSIPE, R.; LOPES, C.L. Avaliação da interferência de plantas daninhas em virtude da época de aplicação de herbicida; diferentes períodos de controle e seletividade à cultura do milho safrinha. In: CONGRESSO BRASILEIRO DE HERBICIDAS E PLANTAS DANINHAS, 23. Gramado, RS, 2002. Resumos... Gramado: SBCPD, 2002. p.74.

PINTO, J.J.O.; SPERANDIO, C.A.; FERREIRA, F.B.; LAMEGO, F.P. Controle de plantas daninhas na cultura do milho com herbicidas de aplicação em pré e pós-emergência. In: CONGRESSO BRASILEIRO DE HERBICIDAS E PLANTAS DANINHAS, 22. Foz do Iguaçu, PR, 2000. Resumos... Foz do Iguaçu: SBCPD, 2000. p.279.

PITELLI, R.A.; GRAVENA, R.; MEROTO JR., A.; BARROS, A.C.; PURÍSSIMO, C.; ZAGONEL, J.; DALBOSCO, M.; KENEBEL, J.; SCHUMM, K. Controle da interferência das plantas dninhas na cultura do milho (Zea mays) com herbicidas aplicados em diferentes épocas. In: CONGRESSO BRASILEIRO DE HERBICIDAS E PLANTAS DANINHAS, 23. Gramado, RS, 2002. Resumos... Gramado: SBCPD, 2002. p.97.

RAMOS, L.R.M. Efeito de períodos de convivência da comunidade infestante sobre o crescimento, nutrição mineral e produtividade da cultura do milho (Zea mays L.). Jaboticabal, UNESP, 1992, 100 p. Dissertação (Doutorado em Agronomia).

ROSSI, I.H.; OSUNA, J.A.; ALVES, P.L.C.A.; BEZUTT, A.J. Interferência das plantas daninhas sobre algumas características agronômicas e a produtividade de sete cultivares de milho. Planta Daninha, Botucatu, v.14, n.2, p.134-148, 1996.

SLVA, M.S.J.; ASMUS, G.L.; CORREA, A.M. Estudo do herbicida nicosulfuron no controle de plantas daninhas na cultura do milho (Zea mays L.). In: CONGRESSO BRASILEIRO DE HERBICIDAS E PLANTAS DANINHAS, 19. Londrina, PR, 1993. Resumos... Londrina: SBHED, 1993. p.148-149.

VELINI, E.D.; FREDERICO, L.A.; BICUDO, S.J.; ANTUNIASSI, U.R. Eficiência de herbicidas pré e pós emergentes iniciais recomendados para a cultura do milho, no controle de plantas daninhas e avaliação de efeitos dos mesmos sobre a produtividade da cultura. In: CONGRESSO BRASILEIRO DE HERBICIDAS E PLANTAS DANINHAS, 19. Londrina, PR, 1993. Resumos... Londrina: SBHED, 1993. p.141-142.

VISWANATH, $\mathrm{H}$. Weed control and efficient use of fertilizer in mayse (Zea mays). Bangalore, Un. of Agricultural Sci., 1977. 

Quadro 1. Tratamentos (nome técnico, nome comercial), ingrediente ativo, formulação (tipo, concentração), dose (ingrediente ativo - i.a., produto comercial - p.c.) e grupo químico dos produtos utilizados no experimento. Marechal Cândido Rondon, 2000/2001.

\begin{tabular}{|c|c|c|c|c|c|c|}
\hline \multicolumn{2}{|c|}{ Tratamentos } & \multicolumn{2}{|c|}{ Formulação } & \multicolumn{2}{|c|}{ Dose } & \multirow[b]{2}{*}{ Grupo Químico } \\
\hline Nome Técnico & Nome Comercial & Tipo & Concentração & $\begin{array}{c}\text { i.a. } \\
\text { (g/ha) }\end{array}$ & $\begin{array}{c}\text { p.c. } \\
\text { (I/kg/ha) }\end{array}$ & \\
\hline 1. Test. Capinada & - & - & - & - & - & - \\
\hline 2. Foramsulfuron & Tribute & WG & $350 \mathrm{~g} / \mathrm{kg}$ & 35,0 & 0,100 & Sulfoniluréias \\
\hline 3. Foramsulfuron & Tribute & WG & $350 \mathrm{~g} / \mathrm{kg}$ & 45,5 & 0,130 & Sulfoniluréias \\
\hline 4. Foramsulfuron/ lodosulfuron & Equip Plus & WG & $300+20 \mathrm{~g} / \mathrm{kg}$ & $36,0+2,4$ & 0,120 & Sulfoniluréias \\
\hline 5. Foramsulfuron/ lodosulfuron & Equip Plus & WG & $300+20 \mathrm{~g} / \mathrm{kg}$ & $45,0+3,0$ & 0,150 & Sulfoniluréias \\
\hline 6. Nicosulfuron & Sanson $40 \mathrm{SC}$ & S.C. & $40 \mathrm{~g} / \mathrm{L}$ & 50,0 & 1250 & Sulfoniluréias \\
\hline 7. Foramsulfuron + Atrazina & $\begin{array}{c}\text { Tribute }+ \text { Atrazinax } \\
500\end{array}$ & $\begin{array}{l}\text { WG + } \\
\text { S.C. }\end{array}$ & $350 \mathrm{~g} / \mathrm{kg}+500 \mathrm{~g} / \mathrm{L}$ & $35,0+1000$ & $0,100+2,0$ & Triazinas \\
\hline 8. Foramsulfuron + Atrazina & $\begin{array}{c}\text { Tribute }+ \text { Atrazinax } \\
500\end{array}$ & $\begin{array}{l}\text { WG + } \\
\text { S.C. }\end{array}$ & $350 \mathrm{~g} / \mathrm{kg}+500 \mathrm{~g} / \mathrm{L}$ & $45,5+1000$ & $0,130+2,0$ & Triazinas \\
\hline 9. Test. sem capina & - & - & - & - & - & - \\
\hline
\end{tabular}

Obs.: Nos tratamentos 2, 3, 4, 5, 7 e 8 adicionou-se adjuvante Hoefix, na dose de 1,5 L/ha .

FONTE: Andrei (1999). 
Quadro 2. Precipitações ocorridas durante a condução do experimento. Marechal Cândido Rondon, 2000/2001.

\begin{tabular}{|c|c|c|c|}
\hline Data & Precipitação (mm) & Data & Precipitação (mm) \\
\hline $13 / 10 / 2000$ & 10 & $20 / 01 / 2001$ & 20 \\
\hline $14 / 10 / 2000$ & 80 & $23 / 01 / 2001$ & 18 \\
\hline $17 / 10 / 2000$ & 33 & $27 / 01 / 2001$ & 03 \\
\hline $21 / 10 / 2000$ & 6,5 & $30 / 01 / 2001$ & 50 \\
\hline $24 / 10 / 2000$ & 16 & $31 / 01 / 2001$ & 23 \\
\hline $27 / 10 / 2000$ & 27 & 01/02/2001 & 40 \\
\hline $01 / 11 / 2000$ & 35 & 02/02/2001 & 04 \\
\hline $02 / 11 / 2000$ & 23 & 03/02/2001 & 18 \\
\hline $10 / 11 / 2000$ & 17 & 04/02/2001 & 02 \\
\hline $11 / 11 / 2000$ & 20 & 06/02/2001 & 32 \\
\hline $13 / 11 / 2000$ & 41 & $13 / 02 / 2001$ & 14 \\
\hline $21 / 11 / 2000$ & 46 & $14 / 02 / 2001$ & 03 \\
\hline 29/11/2000 & 26 & $15 / 02 / 2001$ & 33 \\
\hline 04/12/2000 & 40 & $19 / 02 / 2001$ & 33 \\
\hline $13 / 12 / 2000$ & 10 & $20 / 02 / 2001$ & 70 \\
\hline $14 / 12 / 2000$ & 30 & $21 / 02 / 2001$ & 06 \\
\hline 23/12/2000 & 10 & $23 / 02 / 2001$ & 04 \\
\hline 24/12/2000 & 17 & $24 / 02 / 2001$ & 03 \\
\hline 28/12/2000 & 55 & $26 / 02 / 2001$ & 31 \\
\hline 29/12/2000 & 30 & $14 / 03 / 2001$ & 07 \\
\hline $30 / 12 / 2000$ & 92 & $17 / 03 / 2001$ & 03 \\
\hline 08/01/2001 & 10 & $18 / 03 / 2001$ & 50 \\
\hline $11 / 01 / 2001$ & 50 & $19 / 03 / 2001$ & 25 \\
\hline $12 / 01 / 2001$ & 10 & $20 / 03 / 2001$ & 18 \\
\hline $13 / 01 / 2001$ & 10 & $23 / 03 / 2001$ & 07 \\
\hline $14 / 01 / 2001$ & 30 & 24/03/2001 & 10 \\
\hline $15 / 01 / 2001$ & 04 & $25 / 03 / 2001$ & 27 \\
\hline $16 / 01 / 2001$ & 35 & $27 / 03 / 2001$ & 12,5 \\
\hline $17 / 01 / 2001$ & 03 & $28 / 03 / 2001$ & 04 \\
\hline
\end{tabular}


Quadro 3. Porcentagem média de controle de Euphorbia heterophylla em diferentes épocas após a aplicação dos herbicidas em pós-emergência, na cultura do milho. Marechal Cândido Rondon/PR, 2000/2001.

Tratamentos

Dose

Época de Avaliação / Dias Após a Aplicação

(g i.a/ha)

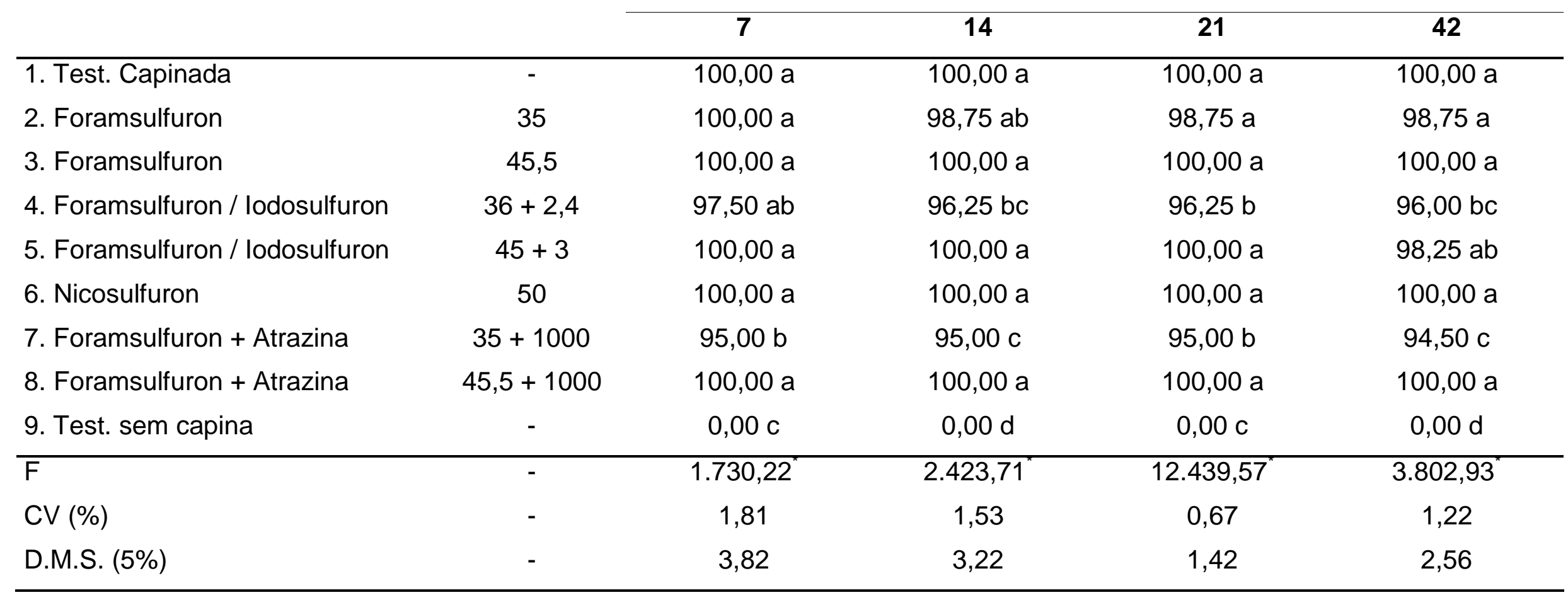

Médias seguidas de mesma letra, na mesma coluna, não diferem estatisticamente entre si pelo Teste de Tukey a 5\% de probabilidade. 
Quadro 4. Porcentagem média de controle de Bidens pilosa em diferentes épocas após a aplicação dos herbicidas em pósemergência, na cultura do milho. Marechal Cândido Rondon/PR, 2000/2001.

Tratamentos Dose Época de Avaliação / Dias Após a Aplicação

(g i.a/ha)

\begin{tabular}{|c|c|c|c|c|c|}
\hline & & 7 & 14 & 21 & 42 \\
\hline 1. Test. Capinada & - & $100,00 \mathrm{a}$ & $100,00 \mathrm{a}$ & $100,00 \mathrm{a}$ & $100,00 \mathrm{a}$ \\
\hline 2. Foramsulfuron & 35 & $98,75 a b$ & $100,00 \mathrm{a}$ & $100,00 \mathrm{a}$ & $97,50 \mathrm{a}$ \\
\hline 4. Foramsulfuron / lodosulfuron & $36+2,4$ & $97,50 \mathrm{~b}$ & $98,75 \mathrm{a}$ & $98,75 \mathrm{a}$ & $97,50 \mathrm{a}$ \\
\hline 5. Foramsulfuron / lodosulfuron & $45+3$ & $100,00 \mathrm{a}$ & $98,75 \mathrm{a}$ & $98,75 \mathrm{a}$ & $100,00 \mathrm{a}$ \\
\hline 7. Foramsulfuron + Atrazina & $35+1000$ & $98,75 a b$ & 98,75 a & $98,75 \mathrm{a}$ & $97,50 \mathrm{a}$ \\
\hline 8. Foramsulfuron + Atrazina & $45,5+1000$ & $100,00 \mathrm{a}$ & $100,00 \mathrm{a}$ & $100,00 \mathrm{a}$ & $100,00 \mathrm{a}$ \\
\hline 9. Test. sem capina & - & $0,00 \mathrm{c}$ & $0,00 \mathrm{~b}$ & $0,00 \mathrm{~b}$ & $0,00 \mathrm{~b}$ \\
\hline $\mathrm{F}$ & - & $6.475,85^{\circ}$ & $10.174,73$ & $4.334,11$ & $2.620,42$ \\
\hline
\end{tabular}

Médias seguidas de mesma letra, na mesma coluna, não diferem estatisticamente entre si pelo Teste de Tukey a 5\% de probabilidade. 
Quadro 5. Porcentagem média de controle de Sida rhombifolia em diferentes épocas após a aplicação dos herbicidas em pósemergência, na cultura do milho. Marechal Cândido Rondon/PR, 2000/2001.

Tratamentos Dose Época de Avaliação / Dias Após a Aplicação

(g i.a/ha)

\begin{tabular}{|c|c|c|c|c|c|}
\hline & & 7 & 14 & 21 & 42 \\
\hline 1. Test. Capinada & - & $100,00 \mathrm{a}$ & $100,00 \mathrm{a}$ & $100,00 \mathrm{a}$ & $100,00 \mathrm{a}$ \\
\hline 2. Foramsulfuron & 35 & $98,75 \mathrm{a}$ & 98,75 a & $98,75 \mathrm{a}$ & $98,50 \mathrm{a}$ \\
\hline 4. Foramsulfuron / lodosulfuron & $36+2,4$ & $98,75 \mathrm{a}$ & $98,75 \mathrm{a}$ & $98,75 \mathrm{a}$ & $98,75 \mathrm{a}$ \\
\hline 5. Foramsulfuron / lodosulfuron & $45+3$ & $100,00 \mathrm{a}$ & $99,50 \mathrm{a}$ & $99,50 \mathrm{a}$ & 99,25 a \\
\hline 7. Foramsulfuron + Atrazina & $35+1000$ & $98,75 \mathrm{a}$ & $98,50 \mathrm{a}$ & $98,50 \mathrm{a}$ & $98,75 \mathrm{a}$ \\
\hline 8. Foramsulfuron + Atrazina & $45,5+1000$ & $100,00 \mathrm{a}$ & $100,00 \mathrm{a}$ & $100,00 \mathrm{a}$ & $100,00 \mathrm{a}$ \\
\hline 9. Test. sem capina & - & $0,00 \mathrm{~b}$ & $0,00 \mathrm{~b}$ & $0,00 \mathrm{~b}$ & $0,00 \mathrm{~b}$ \\
\hline $\mathrm{F}$ & - & $8.096,49$ & $3.181,12$ & $7.506,44$ & $5.987,20$ \\
\hline
\end{tabular}


Quadro 6. Porcentagem média de controle de Brachiaria plantaginea em diferentes épocas após a aplicação dos herbicidas em pós-emergência, na cultura do milho. Marechal Cândido Rondon/PR, 2000/2001.

Tratamentos

Época de Avaliação / Dias Após a Aplicação

\section{Dose}

(g i.a/ha)

\begin{tabular}{|c|c|c|c|c|c|}
\hline \multirow[t]{2}{*}{ Tratamentos } & \multirow{2}{*}{$\begin{array}{c}\text { Dose } \\
\text { (g i.a/ha) }\end{array}$} & \multicolumn{4}{|c|}{ Época de Avaliação / Dias Após a Aplicação } \\
\hline & & 7 & 14 & 21 & 42 \\
\hline 1. Test. Capinada & - & $100,00 \mathrm{a}$ & $100,00 \mathrm{a}$ & $100,00 \mathrm{a}$ & $100,00 \mathrm{a}$ \\
\hline 2. Foramsulfuron & 35,0 & $98,75 \mathrm{a}$ & $98,75 \mathrm{a}$ & $98,75 \mathrm{a}$ & $98,50 \mathrm{a}$ \\
\hline 3. Foramsulfuron & 45,5 & $100,00 \mathrm{a}$ & $100,00 \mathrm{a}$ & $100,00 \mathrm{a}$ & $100,00 \mathrm{a}$ \\
\hline 4. Foramsulfuron / lodosulfuron & $36,0+2,4$ & 98,75 a & $98,75 \mathrm{a}$ & $98,75 \mathrm{a}$ & 98,75 a \\
\hline 5. Foramsulfuron / lodosulfuron & $45,0+3,0$ & $100,00 \mathrm{a}$ & $99,50 \mathrm{a}$ & $99,50 \mathrm{a}$ & 99,25 a \\
\hline 6. Nicosulfuron & 50,0 & $100,00 \mathrm{a}$ & $100,00 \mathrm{a}$ & $100,00 \mathrm{a}$ & $100,00 \mathrm{a}$ \\
\hline 7. Foramsulfuron + Atrazina & $35,0+1000$ & $98,75 \mathrm{a}$ & $98,50 \mathrm{a}$ & $98,50 \mathrm{a}$ & $98,75 \mathrm{a}$ \\
\hline
\end{tabular}




\begin{tabular}{lccccc} 
8. Foramsulfuron + Atrazina & $45,5+1000$ & $100,00 \mathrm{a}$ & $100,00 \mathrm{a}$ & $100,00 \mathrm{a}$ & $100,00 \mathrm{a}$ \\
9. Test. sem capina & - & $0,00 \mathrm{~b}$ & $0,00 \mathrm{~b}$ & $0,00 \mathrm{~b}$ & $0,00 \mathrm{~b}$ \\
\hline F & - & $3.241,35$ & $4.783,70$ & $4.155,64$ & 1,16 \\
CV (\%) & - & 1,32 & 1,08 & 1,41 \\
D.M.S. (5\%) & - & 2,80 & 2,31 & 2,47 & 2,99
\end{tabular}

Médias seguidas de mesma letra, na mesma coluna, não diferem estatisticamente entre si pelo Teste de Tukey a 5\% de probabilidade.

Quadro 7. Porcentagem média de plantas com sintomas de fitotoxicidade (amarelecimento das folhas) e produção (kg/ha) do milho submetido aos diversos tratamentos. Marechal Cândido Rondon/PR, 2000/2001.

\begin{tabular}{|c|c|c|c|c|c|c|}
\hline \multirow[t]{2}{*}{ Tratamentos } & \multirow{2}{*}{$\begin{array}{c}\text { Dose } \\
\text { (g i.a/ha) }\end{array}$} & \multicolumn{4}{|c|}{ Fitotoxicidade (\%)/ Dias Após a Aplicação } & \multirow{2}{*}{$\begin{array}{c}\text { Produção } \\
\text { (kg/ha) }\end{array}$} \\
\hline & & 7 & 14 & 21 & 42 & \\
\hline 2. Foramsulfuron & 35 & 4,3 & 1,0 & 0,0 & 0,0 & $8.750,00 \mathrm{a}$ \\
\hline 3. Foramsulfuron & 45,5 & 5,6 & 1,5 & 0,0 & 0,0 & $9.393,75 a$ \\
\hline
\end{tabular}




\begin{tabular}{|c|c|c|c|c|c|c|}
\hline 4. Foramsulfuron / lodosulfuron & $36+2,4$ & 7,0 & 2,0 & 0,0 & 0,0 & $8.125,00 \mathrm{a}$ \\
\hline 5. Foramsulfuron / lodosulfuron & $45+3$ & 8,7 & 3,0 & 0,0 & 0,0 & $7.843,75 \mathrm{a}$ \\
\hline 6. Nicosulfuron & 50 & 5,8 & 2,0 & 0,0 & 0,0 & $7.968,75 \mathrm{a}$ \\
\hline 7. Foramsulfuron + Atrazina & $35+1000$ & 6,2 & 1,5 & 0,0 & 0,0 & $7.968,75 \mathrm{a}$ \\
\hline 8. Foramsulfuron + Atrazina & $45,5+1000$ & 8,7 & 2,5 & 0,0 & 0,0 & $7.906,25 \mathrm{a}$ \\
\hline 9. Test. sem capina & - & 0,0 & 0,0 & 0,0 & 0,0 & $4.042,50 \mathrm{~b}$ \\
\hline $\mathrm{F}$ & - & - & - & - & - & 6,08 \\
\hline CV (\%) & - & - & - & - & - & 16,52 \\
\hline
\end{tabular}

Médias seguidas de mesma letra, na mesma coluna, não diferem estatisticamente entre si pelo Teste de Tukey a 5\% de probabilidade. 